\title{
Impact Socio-Environnemental De L'exploitation Du Palmier À Huile (Elaeis Gineensis) En Lodjukru Dans La Région De Dabou (Côte d'Ivoire)
}

\author{
Dr. Akmel Meless Siméon
}

Socio-anthropologue, Maître-assistant, Département d'Anthropologie et de Sociologie, Université Alassane Ouattara (Bouaké), Côte d'Ivoire

Doi: 10.19044/esj.2018.v14n3p324 URL:http://dx.doi.org/10.19044/esj.2018.v14n3p324

\begin{abstract}
The operation of the oil palm tree is taking a global scale. In Ivory Coast, people are more involved in the activity because of its importance. The hypothesis of Lodjukru (Snipe region) is for this eloquent purpose, because large areas of oil palms (Traditional, selected) are perceptible everywhere. These are the cases observed in Jasakp, Dibrm and Armebe, which is our field of investigation. The study (qualitative and quantitative) identified the different stages and explained the determinants (socioeconomic value) of the operation of the oil palm tree. It also described and analyzed the environmental problems and health risks associated with the activity.
\end{abstract}

Keywords: Agriculture, oil palm, socioeconomic value, environmental problem, health risk

\section{Résumé}

L'exploitation du palmier à huile prend de l'ampleur au niveau mondial. En Côte-d'Ivoire, les populations s'investissent davantage dans ladite activité, à cause de son importance. L'hypothèse de Lodjukru (région de Dabou) est à cet effet éloquente, car de vastes superficies de palmiers à huile (traditionnels, sélectionnés) sont perceptibles partout. Tels sont les cas observés à Jasakp, Dibrm et Armebe, notre champ d'investigation. L'étude (qualitative et quantitative) a identifié les différentes étapes et expliqué les déterminants (valeur socioéconomique) de l'exploitation du palmier à huile. Elle a également décrit et analysé les problèmes environnementaux et les risques sanitaires liés à l'activité.

Mots-clés: Agriculture, palmier à huile, valeur socioéconomique, problème environnemental, risque sanitaire 


\section{Introduction}

Cet article s'intéresse essentiellement aux problèmes socioenvironnementaux liés à l'exploitation du palmier à huile en pays Jdjukru. En Afrique, l'agriculture occupe une place de choix. Elle est pourvoyeuse d'emplois, et représente dans la plupart des pays une part importante du produit intérieur brut. La Côte d'Ivoire n'est pas épargnée. Au lendemain des indépendances, le pays s'est lancé dans une exploitation intensive des cultures de rentes, tel que le binôme café-cacao. Ainsi, des milliers d'hectares de forêts sont défrichés à cet effet. Dans les années 1960-1970, l'on a assisté à une croissance économique remarquable, considérée comme un miracle ivoirien. Á cette période, le PIB est passé de 2807 millions FF en 1960 à 8280 millions FF en 1970. Dans la même année, le PIB du secteur primaire est passé de 1.220.000.000 FF à 2.253.720.000 FF (Abdoulaye, 1974). Aujourd'hui, le pays est le premier producteur mondial de cacao, avec une production estimée à plus d'1,75 million de tonnes et le troisième au niveau africain, pour ce qui est du café avec 417.000 tonnes (Mays, 2016). Les données montrent que l'agriculture est le moteur du développement en Côte d'Ivoire.

Mais, cette stratégie a entrainé la fragilité de l'économie basée essentiellement sur le café et le cacao, à cause des fluctuations des prix sur le marché mondial. Pour pallier la situation, la diversification des cultures s'est imposée au pays. Le choix a concerné l'exploitation du palmier à huile. Les activités sont alors confiées à la PALMINDUSTRIE, société d'Etat. Mais en 1990, des opérateurs privés (PALMAFRIQUE, PALMCI) rachètent ses actifs et redynamisent le secteur. La culture du palmier à huile occupe actuellement une place de choix dans l'économie ivoirienne. Le pays est le deuxième producteur africain avec 300.000 tonnes et le septième sur le plan mondial, avec 70000 hectares de plantations agro-industrielles et 140.000 hectares de plantations villageoises (Nai, 2000). À l'instar d'autres cultures, l'exploitation du palmier à huile est confrontée à des difficultés d'ordre organisationnel et économique. Akindès (2001) et Cheyns (2000) attribuent les problèmes de la filière à des causes structurelles. Pour eux, les situations d'inconfort se caractérisent par l'absence d'intrants, de matériel végétal sélectionné qui affectent les rendements, la végétation, les producteurs, les consommateurs. Le pays Jdjukru n'est pas en reste, car nombreux sont les planteurs qui sont engagés dans cette exploitation.

Si donc l'exploitation de l'huile de palme rime avec les problèmes socio-environnementaux, les localités rurales qui vivent de cette activité n'y sont pas épargnées. C'est ainsi que nous portons particulièrement notre regard sur le Lodjukru, région fortement marquée par:

-la ruée vers l'activité du palmier à huile. En effet, le travail engendre des revenus substantiels, ayant permis l'amélioration des conditions de vie des 
producteurs, le changement de position sociale et la perpétuation des institutions sociopolitiques;

-les problèmes socio-environnementaux. L'exploitation du palmier à huile a affecté le cadre de vie et exposé les producteurs aux risques sanitaires. Ainsi, la réduction de certains espaces arables, l'odeur nauséabonde dégagée par le ruisseau (kep), les accidents de travail, les maladies dont souffrent les populations sont autant de contraintes liées à cette culture. De ces constats découle une série de problèmes : Comment l'exploitation du palmier à huile, activité essentielle, a-t-elle engendré des problèmes socio-environnementaux chez les Jdjukru? À cette interrogation principale sont rattachées des questions secondaires:

-Quels sont les facteurs qui motivent le travail du palmier à huile en Lodjukru?

-Quelles sont les difficultés environnementales et les contraintes sanitaires en relation avec l'activité? Bref, l'objectif de cette recherche est d'identifier les étapes et de comprendre les déterminants de cette culture, puis d'expliquer les problèmes liés à l'habitat, engendrés par le travail. La thèse soutenue est la suivante : L'exploitation du palmier à huile, source de revenus, menace la nature et expose les Jdjukru aux risques sanitaires.

Notre zone d'enquête est le Lodjukru (basse Côte d'Ivoire) qui compte environ 148874 habitants et couvre environ $2260 \mathrm{~km}^{2}$. Nous avons retenu trois villages: Jasakp, Dibrm, Armebe, à cause de la pollution de la rivière (kep) qui les traverse, des accidents de travail et des maladies enregistrées dans les centres de santé. L'âge nous a permis de déterminer les patriarches, les chefs de terre, les infirmiers, possédant des informations sur la récolte, la fabrication de l'huile, les problèmes de santé. À cela s'est ajoutée la disponibilité des individus. Seules les personnes désireuses de répondre aux questions sur l'exploitation du palmier à huile sont retenues. Nous avons procédé à un choix raisonné pour cibler les personnes ressources à même de nous instruire. Ainsi, 110 enquêtés ont été retenus. Le focus group et le questionnaire sont mobilisés pour recueillir les discours sur les risques sanitaires. Les registres des centres de santé ont aidé à justifier l'existence effective de maladies liées au palmier à huile. Le fonctionnalisme explique l'implication des populations dans l'activité. La théorie de la résilience montre comment les acteurs contournent la pauvreté. La méthode comparative montre les similitudes entre les cultures pérennes, en ce qui concerne les problèmes sanitaires et environnementaux. L'étude est structurée autour de deux parties. La première, identifie les causes liées à la culture du palmier à huile. La seconde explique les contraintes socioenvironnementales dans la localité. 


\section{Les enjeux socio-économiques du palmier à huile}

Ce chapitre justifie l'engouement des paysans Jdjukru pour le palmier à huile. Il vise plus particulièrement à décrire les stades de la production et à comprendre les facteurs liés à la culture. Pour y arriver, nous avons interrogé les enquêtés en ces termes: «Quelles sont les différentes étapes de la culture»? «Qu'est ce qui motive les producteurs»? Voici quelques unes des réponses obtenues:

Autrefois, les parents faisaient du commerce de l'huile de palme, une activité essentielle, parce qu'ils gagnaient bien leur vie. Ils ne se plaignaient pas. Il y a plusieurs étapes : préparer le terrain, planter, entretenir, récolter, puis commercialiser les régimes, l'huile de palme, le savon traditionnel ou kundu (A.G, 60 ans).

Aujourd'hui, l'hévéa bat de l'aile. Le cacao a déjà perdu le terrain. Le palmier à huile rassure, à cause de ses nombreuses utilisations. Qui a une fois mangé le caoutchouc ou croqué les fèves de cacao ou les cerises de café ? Le palmier est incomparable. L'on peut vendre les régimes, fabriquer l'huile rouge et le savon traditionnel, préparer la sauce graine et autres mets succulents. C'est la meilleure culture (E.N, 39 ans).

J'ai choisi le palmier à huile, parce que ses revenus sont mensuels. Il n'y a pas match entre palmier à huile et les autres cultures de rente. Je suis comme un fonctionnaire. J'en suis heureux. Je peux aider les gens. C'est une grande satisfaction. J'ai des comptes en banque. Regardez ma construction et mes petites affaires, ça marche (L.M, 52 ans).

Avec les revenus issus de la vente, je ne regrette pas. Aujourd'hui, je remercie Dieu de m'avoir inspiré. Je me retrouve souvent avec 1200000 FCFA en trois mois de production. Si vous avez à choisir entre le palmier à huile et les autres cultures, $n$ 'hésitez pas à choisir la première, car vous ne regretterez pas ; ça ne ment pas. À la fin du mois, je touche un salaire de 350000 F CFA au moins (M.L, 47 ans).

L'argent de la vente est utilisé pour la scolarisation des enfants. Pour les soins hospitaliers, cet argent me sert. À cela se sont ajoutées les factures d'eau et d'électricité. J'ai construit une nouvelle maison à l'allure moderne. Pour les fêtes de génération, j'ai acheté des bijoux, des pagnes de renom et des parures en or. Je m'occupe bien de ma famille. Les cérémonies traditionnelles étant une occasion pour exhiber les richesses des patriclans et matriclans, je ne me fais pas prier. J'ai énormément investi dans le patrimoine vestimentaire (D.Y, 47 ans).

\section{De ces informations découlent plusieurs remarques}

Les étapes de la culture

L'histoire de la palmeraie de Dabou débute en 1925 avec l'Union Tropicale des Planteurs (UTP). Mais celle-ci dût céder la concession à l'IRHO 
au milieu des années 40 pour y développer une plantation expérimentale sur le palmier à huile. La mise au point d'itinéraires techniques mieux adaptés et un important programme de recherche contre la fusariose ont permis un nouveau départ de la culture dans cette zone au milieu des années 50. Vers 1960, la Côte d'Ivoire cherchant à diversifier son développement agricole, lançait le premier plan Palmier, qui donna un élan sans précédent à cette culture. Avec le choc pétrolier de 1974 s'ouvrait une nouvelle période pour l'huile de palme, avec des cours élevés mais très fluctuants. L'intérêt croissant porté à cette culture dans les années 60-70 s'est également traduit par la mise en place de programmes de replantation de la vieille palmeraie (Caliman, 1998).

Les données susmentionnées exposent l'exploitation du palmier à huile, attestée par Jacquemard (2011) : «le défrichage, l'abattage, le brûlage, l'ensachage, le piquetage, les trouaisons, le planting, l'entretien, la commercialisation». Les différentes photographies présentent certaines étapes de l'activité:

Photo 1. Récolte des palmistes

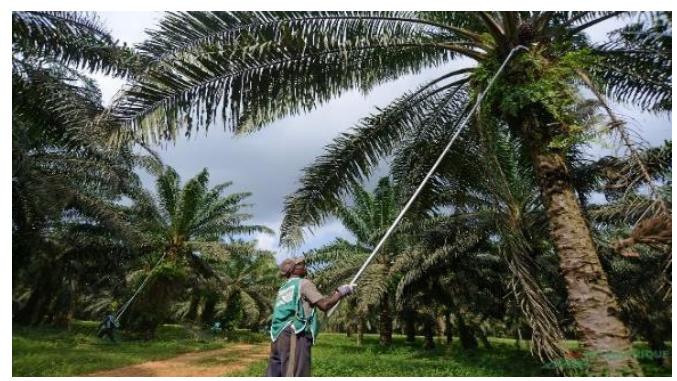

Photo 2. Régimes de palmier à huile

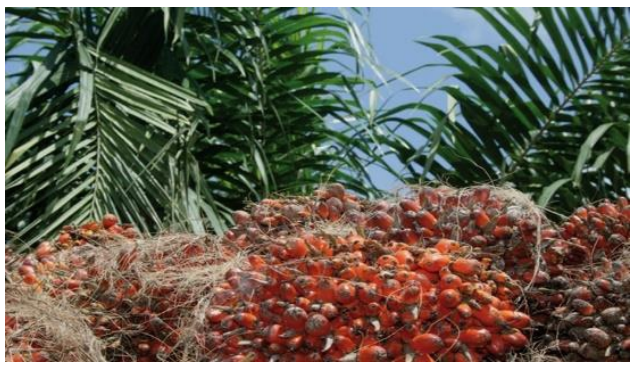

\section{Les déterminants socio-économiques de la plante}

Plusieurs causes dont la valeur économique, motivent l'exploitation du palmier à huile. Elle remonte particulièrement à la période coloniale, où le commerce de la plante a connu un plein essor, ce que nombre d'écrits confirment. En effet, les marchands européens commerçaient avec l'Afrique, mais l'huile de palme n'était qu'occasionnellement importée en Europe, où elle servait d'huile de cuisson, pour la fabrication de savon et de chandelles. Son commerce s'y développait surtout à la fin du XVIII ${ }^{\mathrm{e}}$ siècle, car la révolution industrielle en faisait usage comme lubrifiant mécanique, notamment dans les chemins de fer. Son utilisation en Europe augmenta, lorsque les résidus de noix de palme étaient donnés comme nourriture au bétail, et l'huile de palme servant dans la fabrication de produits pharmaceutiques (Roubaud, 1771).Vers 1870, elle constitue la principale exportation de certains pays d'Afrique de l'Ouest, comme le Ghana et le Nigeria (Aghalino, 2000). En 1885, William Lever fabriqua à Liverpool à échelle industrielle, du savon à base d'huile de palme qu'il importa d'Afrique de l'Ouest (Vacquier, 1986). 
La fabrique de savon Lever Brothers devint par la suite la multinationale 'Unilever', Jusqu'au XIX ${ }^{\mathrm{e}}$ siècle, l'éclairage était assuré par des bougies en suif dangereuses et à la combustion âcre. Les travaux scientifiques de Michel-Eugène Chevreul conduisirent au remplacement de ces chandelles par des bougies stéariques, notamment à base d'huile de palme, comme en fabriqua depuis cette époque l'entreprise londonienne Price's Candles (Volf, 2013). En 1854, elle breveta un procédé de distillation de l'huile de palme qui permit de produire la glycérine utilisée dans de nombreuses compositions pharmaceutiques, cosmétiques et dans les pellicules de photos : la nitroglycérine. Néanmoins, l'huile de palme fut progressivement supplantée par les huiles minérales et les dérivés du pétrole. Elle refit une percée au début du $\mathrm{XX}^{\mathrm{e}}$ siècle dans le domaine de l'industrie alimentaire, qui est aujourd'hui son principal débouché en raison de son faible coût de production, et de ses propriétés physiques et chimiques (Grundmann, 2013).

Á l'instar des pays de l'ouest africain, la commercialisation de l'huile de palme est exercée en pays Jdjukru. Les populations récoltaient les régimes, les pilaient, extrayaient et filtraient l'huile rougeâtre destinée à la vente. Cette substance obtenue par la transformation des palmistes traditionnels était transvasée dans différents instruments. Les colons achetaient l'huile par le truchement d'intermédiaires (sujets) africains. Lorsqu'ils étaient empêchés, les producteurs parcouraient entre 5 et $15 \mathrm{~km}$ pour écouler leur produit. Ainsi, tôt le matin, vers $3 \mathrm{~h} 00$, les femmes transportaient l'huile dans des dames jeannes, quand les hommes poussaient les fûts en direction du chef lieu (Dabou). La rareté des véhicules les y contraignait. L'huile était acheminée vers l'Europe, comme il en est des pays ouest africains suscités. Après l'indépendance, les Ivoiriens se sont appropriés ce commerce, devenue une source de revenus substantiels pour les populations. Grâce à cette activité, les hommes et les femmes se faisaient une santé financière. La production de l'huile de palme a connu un essor, si bien que des familles ont refusé la scolarisation des enfants, car elles ne percevaient pas à court terme l'importance de l'école. Les élèves qui parcouraient des kilomètres pour recevoir la connaissance étaient la risée des jeunes grimpeurs de palmier. Ce qui importait à cette période, c'était comment s'investir davantage dans l'activité pour s'amasser le maximum d'argent, afin de mériter le respect de la communauté villageoise. Trois fois dans le mois, les acteurs récoltaient et transformaient les palmistes. Ces graphiques résument les revenus des producteurs:

Graphique $\mathrm{n}^{\mathrm{O}} 1$. Revenus mensuels de l'huile de palme pendant la colonisation (1946) 


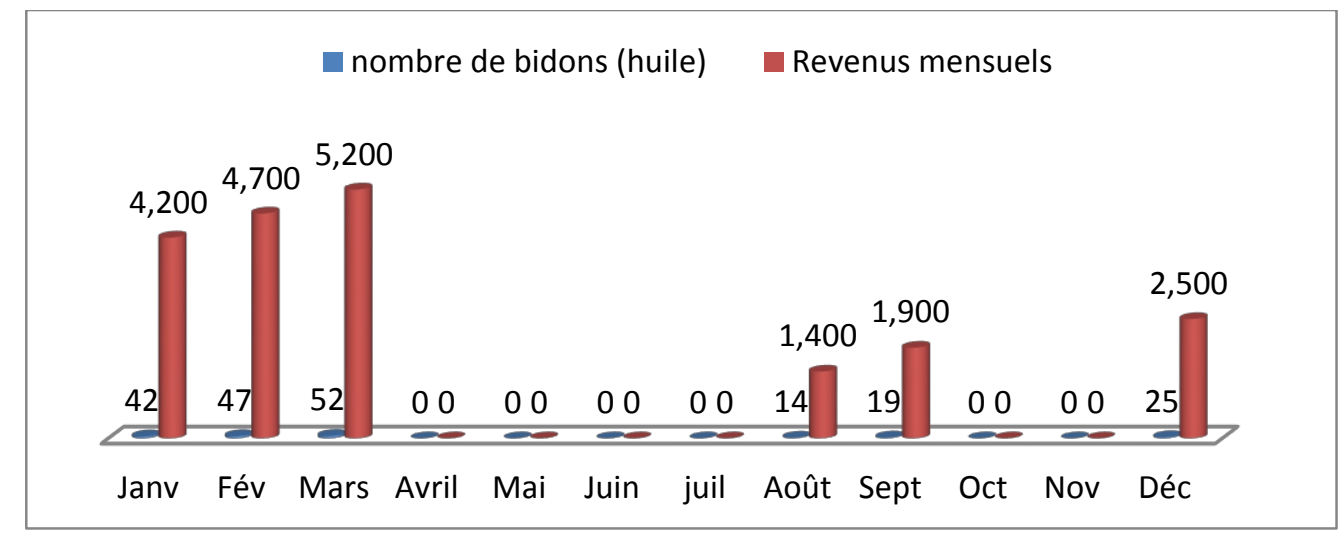

Source : Notre enquête, Jasakp 2016.

Graphique $\mathrm{n}^{\circ} 2$. Revenus mensuels (amandes de palmistes) pendant la colonisation (1946)

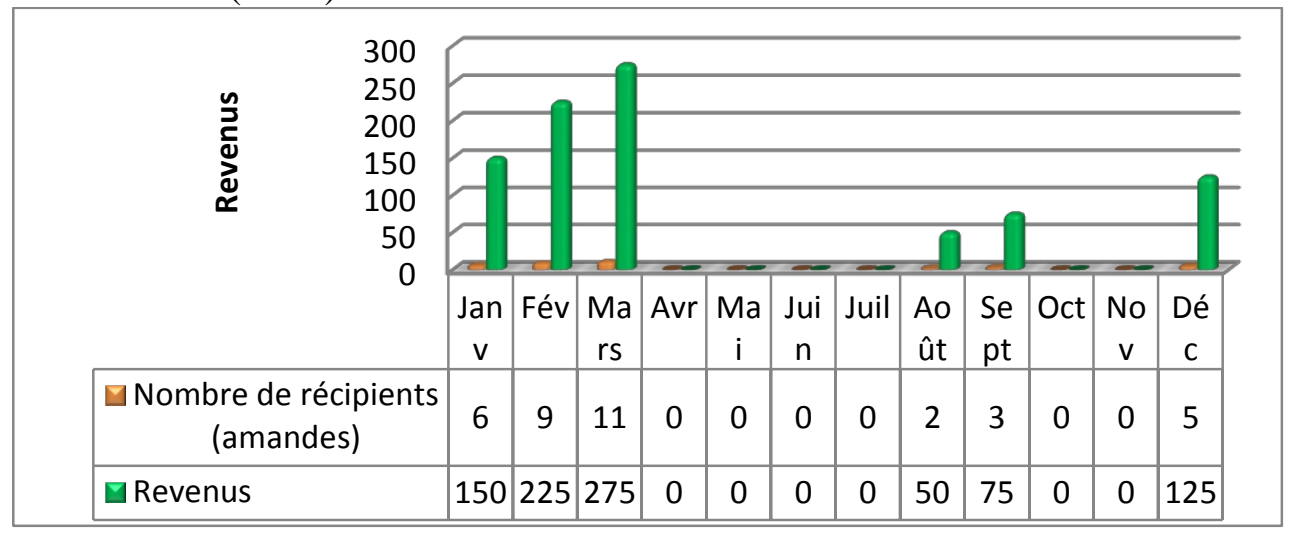

Source : Notre enquête, Jasakp 2016.

L'analyse montre qu'autrefois, l'exploitation des palmiers traditionnels procurait des sommes d'argent aux producteurs Jdjukru. Le prix unitaire d'un récipient en caoutchouc (bidon), en aluminium ou en fer d'une capacité de 20 litres, oscillait entre 25 FF et 200 FF. Nous estimons le prix moyen d'achat à $100 \mathrm{FF}$. Exceptés avril, mai, juin, juillet, octobre et novembre, la production annuelle s'étend sur six mois. Cette situation trouve sa justification au plan géographique. En effet, la grande saison sèche (gbegbn) s'étend de décembre à mars, et la petite saison (fampo), d'août à septembre. Pendant ces périodes, la production de régimes augmente sensiblement et les palmistes mûrissent davantage. Par conséquent, la quantité d'huile obtenue de la transformation des fruits est importante. Les données indiquent qu'entre décembre et mars, la production est passée de 25 à 52 bidons, soit une hausse de 27 bidons. Le montant annuel est estimé à $19900 \mathrm{FF}$, ce qui ne saurait être négligeable à cette époque. L'absence de revenus sur six mois est justifiée par les pluies, qui se répartissent en deux saisons : une grande (njam es us), 
approximativement d'avril à juillet, avec un maximum en juin, et une petite saison de pluie (mew idj) d'octobre à novembre, avec un maximum en octobre (Memel, 1980). Á cette période, les paysans arrêtent les récoltes et vaquent à d'autres occupations, car les troncs d'arbres glissants les exposent aux chûtes mortelles. Les revenus des populations proviennent également du concassage des graines de palmistes, activité essentiellement féminine. Les amandes triées par les femmes et leurs enfants sont vendues, à raison de $25 \mathrm{FF}$ (prix unitaire) les 10 kilogrammes. Elle est exercée sur un semestre avec des interruptions dues aux saisons pluvieuses. Apparemment, les revenus semblent insignifiants, puisqu'ils n'excèdent pas annuellement 20000 FF. Cependant, pour la période concernée ils sont importants, car l'insécurité alimentaire ne s'est pas posée. Les superficies réservées aux cultures vivrières sont étendues, à perte de vue. Aussi, l'exploitation intensive des surfaces n'a pas existé, car l'activité essentielle était la fabrication de l'huile de palme et le concassage des graines de palmistes. La démographie n'ayant pas connu une croissance exponentielle, les conflits fonciers ne sont pas récurrents. En 1966, la Souspréfecture de Dabou comptait 37000 habitants (Memel, 1980). Si à cette époque la population est moins nombreuse, imaginons celles des zones d'étude pendant la colonisation. Ces facteurs ont longtemps favorisé la cohésion sociale et la solidarité agissante, voire ''le chacun pour tous, tous pour tous, Dieu pour tous', , pour emprunter l'expression à Moustapha (1999). Le niveau de vie est également faible, tandis que les ressources halieutiques, cynégétiques, agricoles sont abondantes. Ainsi avec $1 \mathrm{FF}$, les populations ont la possibilité de faire des emplettes et vivre convenablement. Aujourd'hui, même s'il existe une fabrication artisanale, l'activité, devenue insignifiante est essentiellement destinée à l'alimentation. Elle ne représente plus une source de richesse, parce que les palmiers naturels sont abusivement abattus au profit des cultures de rente et des produits vivriers. $\dot{A}$ cela s'ajoute la valeur socioculturelle.

En pays Jdjukru, le travail de la plante est un moyen d'intégration et de socialisation de l'individu. Grimper aux palmiers de 15 à $22 \mathrm{~m}$ de hauteur, au travers d'une ceinture en liane est un acte de bravoure. Le paysan doit donc s'armer de patience, de courage avant et pendant la récolte, car l'activité est périlleuse. L'on a enregistré des chutes ayant occasionné des pertes en vies humaines. Les plus chanceux sont marqués à vie par de graves blessures. Dans la société ancienne, où des vertus (courage, persévérance, travail, respect) sont enseignées, les paresseux sont de facto exclus de certains privilèges (mariages, honneurs). C'est pourquoi des hommes sont demeurés célibataires sans progénitures, car aucune famille n'accepte de donner en mariage leur fille à une personne non vertueuse. Les jeunes grimpeurs, considérés comme des modèles de réussite sont acceptés et intégrés dans les familles et les lignages de l'épouse. Ȧ cette période, l'activité du palmier à huile est essentiellement 
intervenue dans la vie quotidienne des paysans. Les propos des enquêtés attestent que:

Avec l'huile de palme, nous gagnions de l'argent. On prenait pour payer à manger pour la famille. On s'occupait des enfants et de nous-mêmes. Quand les gens arrivaient, il fallait aussi payer l'impôt. Quand les commerçants venaient, on payait aussi les gros pagnes pour garder. Plus tard, les enfants vont porter. Regardez dans le village, vous voyez des maisons en dur, c'est l'argent du palmier à huile. Pour faire la dot, on utilisait l'argent du palmier (A.E, 80 ans ; B.A, 75ans).

Ces informations montrent la fonction socioculturelle de l'activité. En effet, les revenus de l'huile de palme et du concassage des palmistes sont utilisés pour la satisfaction des besoins quotidiens. Nous distinguons l'alimentation, le paiement d'impôts, les soins de santé, l'entretien des enfants, ce que Maslow (1943) appelle 'besoins essentiels". Dans sa pyramide, il permet de situer en premier besoin fondamental, les besoins physiologiques, à savoir : boire, manger, dormir... Sans l'accomplissement de ces besoins de base, il n'y a pas, ou plus de vie, plus d'humanité, mais aussi plus de capacité de progression. Aujourd'hui, leur absence a conduit des hommes solides et psychologiquement résistants à la déchéance, la trahison, la mort (Berger, 2008). Les revenus du palmier à huile ont également permis à des producteurs de changer de position sociale. Ils sont sollicités et interviennent dans les programmes de développement local. Ils disposent de maisons modernes qui donnent une allure de villes aux localités. En outre, les sommes d'argent ont servi à la scolarisation des enfants dont certains sont envoyés en Europe. De retour de leurs formations, ils ont occupé des postes de responsabilité. Hauts cadres de la nation, ils font la fierté des parents, de leurs villages et leur région.

L'activité du palmier à huile intervient, enfin, dans la perpétuation des institutions sociopolitiques : low, dedjakp, âgbâdji, $\varepsilon b$-eb. Les revenus ont servi à l'achat de pagnes de renom, de parures, de cannes, de chapeaux en or ou argent. Chaque famille ou lignage dispose d'un patrimoine vestimentaire

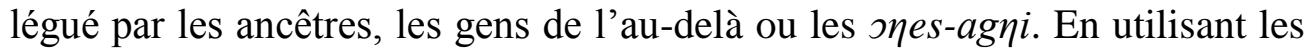
legs, les vivants entrent en contact, en communion, en communication avec les disparus, et ont pour mission d'enrichir ce patrimoine. En clair, les trépassés ne sont pas partis. Birago (1960) affirme que:

Ceux qui sont morts ne sont jamais partis. Ils sont dans l'ombre qui s'éclaire, et dans l'ombre qui s'épaissit. Les morts ne sont pas sous la terre. Ils sont dans l'arbre qui frémit. Ils sont dans le bois qui gémit. Ils sont dans l'eau qui coule. Ils dans la case, ils sont dans la foule. Les morts ne sont pas morts.

Pendant les cérémonies initiatiques, de maternité, de noblesse ou du sacre des gouvernants, les populations se parent de leurs plus beaux habits, fruit de leur labeur. La mobilisation des acteurs lors des pratiques sociales 
cycliques, en exhibant leurs richesses participe implicitement à la pérennisation des institutions sociopolitiques. De ce fait, l'exploitation du palmier à huile remplit une fonction latente (invisible), voire culturelle. Si cette activité intervient énormément dans la vie économique et socioculturelle des paysans, elle a aussi occasionné des situations d'inconforts.

\section{Les contraintes environnementales et sanitaires}

Cette partie de l'étude analyse l'impact de l'exploitation du palmier à huile sur 1'homme et son environnement. Pour y arriver, nous avons interrogé les enquêtés en ces termes : «Quels sont les problèmes occasionnés par le travail du palmier à huile» «Quelles en sont les conséquences»? Voici quelques-unes de leurs réponses :

Il existe des plantations familiales, des plantations collectives et des plantations industrielles. Les graines sont transformées pour obtenir l'huile de palme. Les déchets ou résidus déversés par la société palmindustrie atteignent le cours d'eau naturel appelé ksp, qu'on consommait. Aujourd'hui, on ne peut plus boire de cette eau. Elle est sale et ça sent mauvais (E.A, 32 ans ; G.Y, 62 ans).

La nuit, on n'arrive pas à dormir paisiblement. Les moustiques pullulent partout. Vous comprenez donc les effets collatéraux, c'est-à-dire le paludisme. Chaque jour, il faut mettre insecticide. Avec l'odeur, cela donne des maux de tête pas possibles. Mais on fait avec pour ne pas attraper la maladie (L.N, 40 ans ; B.L, 79 ans).

Les enfants qui se baignent dans la rivière se retrouvent avec la gale sur le corps, les démangeaisons de la peau. La mauvaise odeur qui se dégage de l'eau est insupportable. Voilà pourquoi nous avons affaire aux moustiques. Nous sommes obligés de dormir sous des moustiquaires imprégnées, parce que le paludisme, ça ne connaît pas ici, on en souffre. Il y a d'autres maladies encore (A.B, 29 ans).

Le paludisme est la première maladie qui affecte les populations jeunes et vieilles dans le village. La prévalence est justifiée par les déchets qui pullulent partout, les odeurs nauséabondes dégagées par les cours d'eau, sans compter la gale chez les enfants, puisqu'ils vont se baigner dans la rivière. Le travail de l'huile rouge n'est pas aussi facile qu'on le pense. Autrefois les grimpeurs tombaient de l'arbre et mouraient. D'autres se cassaient les membres s'ils ont la chance de vivre. Ce n'était pas bien à voir, mais ils $n$ 'avaient pas le choix. Il fallait survivre (E.D, 71 ans, M.O, 53 ans). L'analyse des données indique deux contraintes liées à l'activité dans les zones d'étude :

\section{Les problèmes environnementaux}

À l'indépendance du pays en 1960, hormis la palmeraie naturelle exploitée à Dabou, il n'existait que quelques plantations industrielles. Nous 
distinguons 1950 ha appartenant à la savane de Dabou, 1727 ha de l'institut de recherches pour les huiles et oléagineux à Mopoyem (Jannot, 2010). Aujourd'hui, les superficies du palmier à huile sont disséminées partout et atteignent environ 8000 hectares. Les plantations traditionnelles, hier source de revenus ont disparu, à cause des exploitations intensives des cultures de rente. De ce fait, le palmier sélectionné a 'avalé' les espaces arables réservés aux viviers. Le manioc, aliment de base des populations connait une baisse drastique de sa production. Les études que nous avons entreprises dans certains villages Jdjukru sont expressives. En 2001, le manioc a occupé dans les zones d'étude 76 hectares et 92 hectares pour l'hévéaculture. Les productions sont estimées respectivement à 2280 tonnes de tubercules et 92 tonnes de latex. En 2016, les superficies du manioc ont connu une régression (40 hectares et 1200 tonnes de racines tubéreuses), celles de l'hévéa ont progressé (197 hectares et 197 tonnes de latex).

L'importance alimentaire du manioc chez les populations est attestée par Akmel (2005). En effet, pendant la phase préparatoire du dediakp, l'attiéké disposé dans des paniers est offert à des membres de la communauté villageoise. Au cours de l'initiation, l'essentiel des mets repose sur le manioc. En ce qui concerne le $l o w$, les parents du récipiendaire offrent des récipients contenant de l'attiéké avant la cérémonie. Pendant le rituel, des aliments, particulièrement à base de manioc sont consommés par les candidats, les membres des classes d'âge aînées et subalternes (une semaine d'affilée, matin et soir). Concernant l'âgbâdji, le constat est le même. Avant l'initiation et pendant la toilette du récipiendaire, deux semaines durant, les membres des lignages, ceux des classes d'âge déjà initiés ou non s'alimentent principalement en attiéké. L'eb-eb n'est pas épargnée, car depuis la phase préparatoire, jusqu'à la période initiatique, la semoule de manioc constitue la nourriture de base. Dérivé de la transformation des racines tubéreuses, l'attiéké s'est raréfié tant au niveau local que national en 2015. Cet enquêté atteste que:

S'inquiéter pour le lendemain est indispensable, car il n'existe presque plus de forêt. Le comble, c'est qu'à l'allure où nous allons, la famine nous guette. Nous n'aurons plus de cultures vivrières comme le manioc, la banane, l'igname, chez nous. Cela nous chagrine beaucoup.

Se procurer cette denrée à moindre coût n'est pas chose aisée, ce qui a entraîné une hausse du prix d'achat. Cette situation d'inconfort a amené des ménages à modifier leurs habitudes alimentaires. Ainsi, le riz nourriture secondaire a supplanté l'attiéké, ce qui a engendré des frais supplémentaires chez les Jdjukru. La réduction considérable des espaces cultivables et ses conséquences sont similaires à celles rencontrées dans d'autres régions de Côte d'Ivoire. Dea (2013) affirme que :

Certains paysans de cette zone sont obligés d'aller chercher des parcelles ailleurs pour y cultiver des plantes nourricières, qu'ils reviennent 
ensuite vendre dans le département. Toute la nourriture de Bettié vient donc du pays Akyé au-delà du fleuve Comoé où encore d'Apprompronou à une centaine de kilomètres plus loin au Nord, voire d'Abidjan. Ce qui se répercute forcément sur le prix des denrées. Dans les restaurants de cette petite localité brusquement projetée à l'état de ville grâce à l'hévéaculture, le plat dans les restaurants se négocie à partir de 1000 FCFA contre 300 FCFA à

Abengourou par exemple. L'ANADER confirme également cette observation, et fait le constat que la courbe de production du vivrier est décroissante. Ainsi, de 2008 à 2009, la production de manioc dans le département d'Abengourou est passée de 266628 tonnes à 160670,5 tonnes soit une baisse de 39.73\%. Cette décroissance peut être constatée au niveau du riz, du maïs, de la tomate.

La diminution des superficies des cultures vivrières soulève le problème de la sécurité alimentaire. Ce qui paraît paradoxal, c'est l'attitude ambivalente des autorités politiques et administratives. En effet, pendant qu'elles encouragent les populations à s'investir davantage dans les cultures vivrières, au travers des médias pour prévenir la famine, au même moment, elles achètent des centaines d'hectares de forêts. Les superficies sont exploitées au profit des cultures de rente, particulièrement l'hévéa et le palmier à huile. De ce fait, la politique agricole menée depuis les indépendances vise essentiellement l'exportation des produits de rente, en vue de renflouer les caisses de l'Etat. C'est donc la croissance économique qui est la première préoccupation nationale. Nous comprenons dès lors que le pays occupe le premier rang mondial des producteurs de cacao. En vue de satisfaire les désirs des 'nouveaux colons, sempiternels donneurs de leçons,', des forêts sont abusivement vendues et défrichées au profit des cultures de rente, notamment dans le Lodjukru. Les études de Kangah (2012), concernant l'hévéaculture sont éloquentes. L'auteur soutient que les surfaces occupées par les plantations villageoises d'hévéa ont eu une très nette évolution. De moins de 300 ha en 1987, les surfaces couvertes par la culture de l'hévéa sont passées à plus de 500 ha en 2000, avant d'atteindre plus de 1.100 ha en 2016, soit un accroissement (plus de 800 ha), ce qui correspond à un taux d'évolution global de plus de $300 \%$. Cette stratégie marginalise les cultures vivrières, si bien que malgré la dissémination des bas fonds, le riz est encore importé en Côte d'Ivoire. À la réduction du couvert végétal destiné à la nutrition des populations s'ajoute la pollution de l'environnement. La PALMINDUSTRIE, ex société d'Etat devenue PALMCI, a installé une usine de transformation des palmistes à Jasakp. Elle fabrique l'huile de palme destinée à certaines entreprises des grosses agglomérations dont Abidjan. Mais les déchets

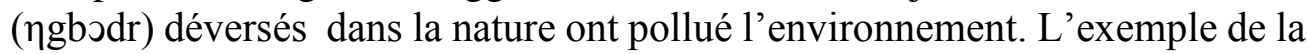
rivière (kep) en est une illustration. Traversant le village de Jasakp (en amont), elle coule en direction de Dibrm et Armebe (en aval). L'observation directe 
permet de découvrir des résidus d'huile sur la surface de l'eau, dégageant une odeur nauséabonde. Autrefois destinée à la consommation des ménages, la rivière est aujourd'hui polluée par les déchets déversés depuis Jasakp. Les propos des enquêtés expriment l'amertume :

Cette eau nous servait. On partait à la rivière pour se baigner, on s'y rendait pour la lessive et la vaisselle, même la pêche à l'hameçon. On puisait l'eau pour la cuisson et la consommation. Depuis l'installation de cette usine dans le village voisin (Jasakp), tout est fini. C'est l'eau de la SODECI que nous buvons. Plus de baignade pour les adultes, plus de lessive parce que l'eau dégage une odeur désagréable, ça sent mauvais (K.P, 78 ans ; L.B, 67 ans).

La pollution du cadre de vie par les entreprises n'est pas spécifique aux Jdjukru. Les effets néfastes des agro-industries sur l'écosystème sont rencontrés partout dans les sociétés modernes. En effet, les intrants utilisés dans la lutte contre les insectes, les plantes nuisibles améliorent sensiblement les productions agricoles. Transformées dans des usines, elles ont engendré des conséquences désastreuses sur l'environnement. Nous citons en exemple la SOGUIPAH, qui a occasionné la perturbation des écosystèmes et les maladies dont souffrent des populations rurales guinéennes. La FAO (2000) soutient également que le lactosérum, produit indésirable, coûteux à éliminer est en général simplement déversé dans les cours d'eau, ce qui a des conséquences regrettables pour l'environnement. On estime qu'une fromagerie produisant 250000 litres de lactosérum par jour pollue autant d'eau qu'une ville de 50000 habitants. Malgré leur importante contribution au développement agricole et rural, les agro-industries peuvent produire des effets secondaires nuisibles à l'environnement. En l'absence de précautions, elles sont susceptibles de polluer l'environnement ou comporter des risques divers; de rejeter des déchets organiques dangereux qui polluent les eaux. Elles peuvent émettre la poussière ou le gaz qui détériorent la qualité de l'air et produisent des substances toxiques. C'est également la position de AnovaPlus (2014) :

La culture intensive est un système de production agricole fondé sur l'optimisation de la production par rapport à la surface cultivée. Cette méthode repose sur une mécanisation poussée ainsi que de l'usage d'engrais chimiques, de pesticides, de fongicides et d'herbicides, afin de maximiser la production. Ce mode de production assure un rendement important des cultures, ce qui permet de nourrir une population mondiale toujours plus nombreuse ; mais il met en péril la biodiversité et la santé humaine, en étant responsable de la pollution des sols, des nappes phréatiques et des cours d'eau souterrains. Le palmier à huile a aussi engendré des maladies chez les Jdjukru : 


\section{Les problèmes sanitaires.}

Les résidus ou déchets issus de la transformation des palmistes, déversés par la PALMCI ont recouvert la surface de la rivière $k \varepsilon p$. Les odeurs et l'insalubrité du cours d'eau situé à proximité des zones d'étude engendrent des maladies. L'exemple de Dibrm confirme ces propos:

Graphique 3. Les maladies contractées par les populations

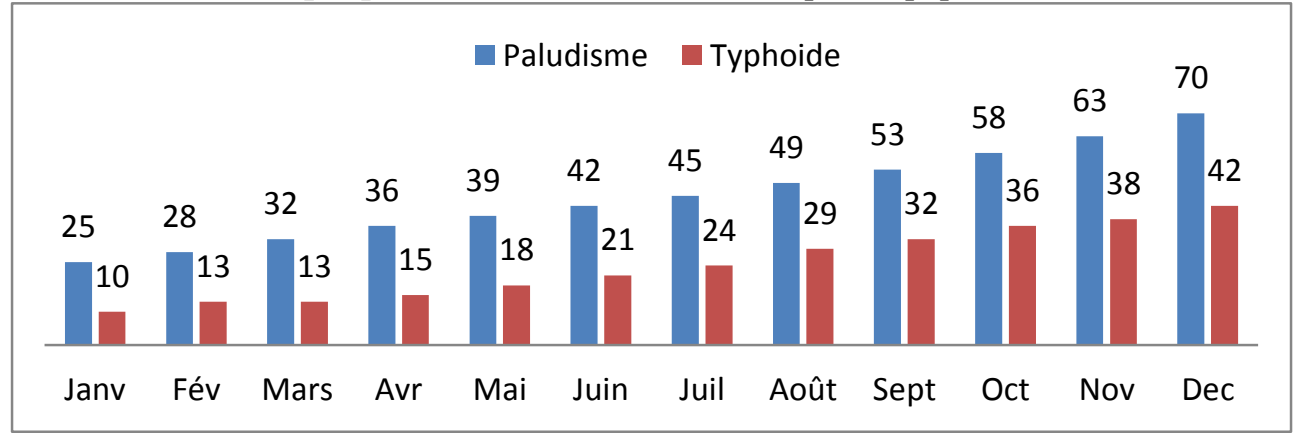

Il ressort des données du terrain et celles du registre de la zone d'étude, différentes maladies, dont la plus importante est le paludisme. Cette prééminence est justifiée par l'existence d'ordures. Une étude sur la localité confirme la relation entre la maladie, les déchets ménagers et leur mauvaise gestion. En effet, l'accumulation des immondices, l'écoulement des eaux usées provenant de l'essorage du manioc ou des fosses sceptiques constituent un gite larvaire déplorable, car les moustiques s'y développent et se multiplient dans les milieux insalubres. Les dépôts anarchiques des déchets à proximité des habitations, des établissements scolaires et sanitaires, aires de jeux d'enfants, les eaux de ruissellement se déversant dans les marigots... sont autant de facteurs exogènes de la pathologie. Des spécialistes attestent que:

La prolifération des maladies telles que le paludisme, la typhoïde et les maladies diarrhéiques est inévitable à Dibrm, car les dépotoirs se mêlent aux habitations. Ils sont confondus aux maisons. En effet, à l'arrière de certaines habitations se trouvent ces décharges publiques. Par ailleurs, les eaux usées nourries par les eaux de vaisselle, de toilette, et surtout celles issues de la semoule du manioc, représentant des nids de moustiques stagnent devant les concessions et sont sources des maladies précitées. La population la plus affectée par le paludisme, la typhoïde et la diarrhée reste les enfants et les femmes (T.S, 35 ans).

Les causes sont multiples, mais se résument en "une"' la mauvaise gestion des ordures ménagères, le manque d'hygiène de la population. Vous constaterez par vous-même, les différents dépotoirs qui sont à l'intérieur du village et non en dehors. Les enfants y jouent comme ils veulent, or toutes sortes d'ordures y sont jetées, surtout les matières fécales. Pendant les saisons de pluies, la situation est encore plus grave. Les dépotoirs étant en hauteur, 
certains villageois reçoivent par le biais de l'eau de ruissellement les matières fécales, et autres ordures dans leurs maisons. Tirez en vous-même les conséquences de cette situation (D.H, 40 ans).

Le paludisme est également occasionné par l'insalubrité de la rivière. Son implication dans la maladie est justifiée par les résidus de l'huile de palme sur la surface de l'eau située non loin des zones d'étude. Dégageant une mauvaise odeur, il constitue un lieu propice à la prolifération des moustiques, parce qu'ils y déposent leurs larves. Chaque année, 1,3 millions de personnes, dont $90 \%$ d'enfants de moins de cinq ans meurent de paludisme. L'eau et l'assainissement sont indispensables à la santé publique, puisqu'ils constituent la base de la maladie. La garantie des conditions de vie pour chacun, l'accès à une eau salubre et à un assainissement correct sont indispensables à la lutte contre la pathologie. Une bonne gestion des ressources hydriques réduit la propagation du paludisme et d'autres maladies à transmission vectorielle (Lee, 2004).

Les données montrent enfin l'existence de la fièvre typhoïde, particulièrement chez les enfants. En effet, à longueur de journée, ils se baignent dans la rivière, aire de jeux, malgré l'insalubrité de l'eau, et sont exposés à des bactéries. Pendant les repas, nombreux sont ceux qui omettent de se laver les mains. Au travers de leur imprudence, les enfants souillent les aliments qu'ils consomment, se contaminent et contractent la maladie. L'OMS (2017) atteste que :

La fièvre typhoïde est causée par la bactérie Salmonella typhi dont les germes passent dans les selles et l'urine des personnes infectées. Elles sont infectées après avoir consommé des aliments ou des boissons, qui ont été manipulés par une personne infectée, ou par de l'eau de boisson qui a été contaminée par des effluents contenant les bactéries. Lorsqu'elles pénètrent dans l'organisme d'une personne, elles se multiplient et se propagent des intestins vers le courant sanguin.

Pendant la récolte des palmistes traditionnels, les Jdjukru, ceintures en liane, enlacées autour de la hanche grimpent aux arbres. Les régimes arrivés à maturité sont cueillis au travers de ciseaux (luru) et d'une machette (lab). Mais des accidents de travail sont signalés partout dans les zones d'étude. Les informations recueillies confirment de nombreux décès et des traumatismes dus aux chutes de grimpeurs. À cela se sont ajoutées des piqûres d'araignées venimeuses (amygdalines), les blessures occasionnées par les outils tranchants (machette) qui ont affecté la santé des producteurs. Le travail du palmier à huile expose donc le producteur à des risques. Le BIT (2000) confirme la dangerosité des activités. Il montre que l'agriculture est une des professions les plus dangereuses à travers le monde. Dans plusieurs pays, le taux d'accidents mortels y atteint le double de la moyenne de tous les autres secteurs réunis. Selon les estimations, chaque année les travailleurs sont victimes de 250 
millions d'accidents. D'un total mondial de 335.000 accidents mortels sur le lieu de travail, 170.000 victimes sont des travailleurs agricoles. L'usage intensif de machines agricoles et de pesticides et autres produits chimiques a accru les risques. Les taux de fréquence de lésions graves et de mortalité par accidents les plus élevés sont dus aux machines, telles que les tracteurs et les moissonneuses. L'exposition aux pesticides et autres produits chimiques constitue l'un des principaux risques professionnels. Ceux-ci sont responsables d'intoxication, de mort et, dans certains cas, de troubles de la fonction reproductive. La leçon qu'il convient de tirer est la déconstruction de la politique agricole ivoirienne, afin qu'elle prenne en compte la préservation de la biodiversité et la valorisation des cultures vivrières, un potentiel économique.

\section{Conclusion}

La recherche de bien-être a amené les populations Jdjukru d'hier à exploiter le palmier traditionnel pour contourner la pauvreté. La fabrication de l'huile et le concassage des palmistes sont devenus une activité pourvoyeuse de revenus substantiels à cette époque. Mais en même temps, le travail leur a permis de satisfaire certains besoins socioculturels. De ce fait, l'exploitation du palmier à huile remplit à la fois une fonction manifeste (source de richesse, amélioration des conditions de vie), et une fonction latente (soutien aux rites initiatiques). Malgré cette importance, l'activité représente une richesse risquée, car le travail a engendré des problèmes environnementaux (problème d'insécurité alimentaire, pollution) et des risques sanitaires (paludisme, typhoïde, accidents). Ces problèmes sont similaires à ceux rencontrés dans d'autres localités. Bref, si donc l'exploitation de l'huile de palme, source de richesse menace l'environnement et affecte la santé des populations, l'activité nécessite une analyse critique pour adapter le travail à l'homme et au cadre de vie.

\section{References:}

1. Abdoulaye, Sawadogo (1974). La stratégie du développement de l'agriculture en Côte d'Ivoire. Bulletin de l'Association des Géographes Français, 51 (415) : 87-103.

2. Aghalino, Samuel Ovete (2000). British Colonial Policies and the Oil Palm Industry in the Niger Delta Region of Nigeria, 1900-1960. African Stydy Monographs, 21, 19-33.

3. Akindès, Francis \& Kouamé, Yao Sévérin (2001). Les ajustements dans l'économie de plantation villageoise de palmier à huile face à la privatisation de la filière en Côte d'Ivoire. Oléagineux, Corps Gras, Lipides, 8 (6) : 636-640. 
4. Akmel, Meless Siméon (2005). Impact socio-sanitaire de l'exploitation du manioc (Manihot esculenta Crantz) sur les populations paysannes en pays Odjukru dans la région de Dabou. Thèse de l'Université de Bouaké, Côte d'Ivoire, 404 p.

5. Anova-Plus (2014). Culture intensive : les conséquences. Anova-Plus. http://anova-plus.cpm/blog/culture-intense-les-consequences/, consulté le 13/06/2017.

6. Berger, Jean-François (2008). Les besoins de l'homme. Essai d'après Abraham Maslow. Paris, Dadga, 21 p.

7. Birago, Diop (1960). Le souffle des ancêtres, leurres et lueurs. Paris, Présence Africaine, $88 \mathrm{p}$.

8. BIT (2000). Sécurité et santé dans l'agriculture. Genève, BIT, p.3.

9. Caliman, Jean-Pierre \& Aubry, Michel (1998). Passé et avenir du palmier à huile dans la savane de Dabou (Côte d'Ivoire). Oléagineux Corps gras Lipides, 5 (2) : 113-115.

10. Cheyns, Emmanuelle \& Akindès, Francis (2000). La filière palmier à huile en Côte d'Ivoire, 3 ans après la privatisation : état des lieux d'un procès de recomposition institutionnelle. Regards, 7 (2) : 166-171.

11. Dea, Armand (2013). Indénié-Djuablin : comment l'hévéaculture affame les populations. abidjan.net.http://news.abidjan.net/h/479330.html, consulté le $13 / 01 / 2017$.

12. FAO (2000). La situation mondiale de l'alimentation et l'agriculture. Rome, FAO, 329 p.

13. Grundmann, Emmanuelle (2013). Un fléau si rentable : vérités et mensonges sur l'huile de palme. Paris, Calmann-Lévy, 264 p.

14. Jacquemard, Jean-Charles (2011). Le palmier à huile. Paris, Claire Parmentier, $240 \mathrm{p}$.

15. Jannot, Claude (2010). Emplois, économie, environnement : le développement de la filière palmier à huile en Côte-d'Ivoire. CIRAD, 17 (6) : 393-399.

16. Kangah, Armand ; Konan, Kouadio Eugène \& al ( 2012). Cartographie par télédétection et analyse de l'influence des activités agricoles dans le terroir villageois odjoukrou à l'ouest d'Abidjan, Côte d'Ivoire. Regardsuds, 29, 1-15.

17. Lee, Jong-Wook (2004). L'eau, l'assainissement, l'hygiène et la santé. OMS. http://www.who.inter/water, consulté le 13/06/2017.

18. Maslow, Abraham Harold (1943). A Theory of Human Motivation. Psychological Review, 50 (4) : 370-396.

19. Mays, Mouissi (2016). Afrique : classements des pays producteurs de matières premières. Maysmouissi.com. https://www.mays- 
mouissi.com/2016/02/23/afrique-classements-des-pays-producteursde-matieres-premieres/, consulté le 12/06/2017.

20. Memel, Foté Harris (1980). Le système politique de Lodjukru : une société lignagère à classes d'âge. Paris, Présence Africaine, $479 \mathrm{p}$.

21. Moustapha, Diabaté (1999). L'Indicamétrie capacitaire. Bouaké, CUMERFI, $22 \mathrm{p}$.

22. Nai, Nai Serge \& Cheyns, Emmanuelle (2000). Adoption du palmier à huile en Côte d'Ivoire. $O C L, 7$ (2) : 155-165.

23. OMS (2017). Les maladies liées à l'eau. OMS. http://www.who.int/water_sanitation_health/, consulté le 13/06/2017.

24. Roubaud, Pierre Joseph André (1771). Histoire générale de l'Asie, de l'Afrique et de l'Amérique, Des Ventes de la Doué, $1: 460$.

25. Vacquier, Raymond (1986). Au temps des factoreries, 1900-1950. Paris, Karthala, 395 p.

26. Volf, Elie \& Chevreul, Michel-Eugène (2013). Un savant, doyen des étudiants de France - Des corps gras et de la chandelle à la perception des couleurs. Paris, Harmattan, 336 p. 